\title{
"DO QUE QUE EU ESTOU FALANDO QUANDO FALO DOS MEUS CESTOS": CONVERSAS COM MABEL MCKAY ${ }^{1}$
}

GREG SARRIS ${ }^{2}$

$U C L A$

\begin{abstract}
Numa manhã de fevereiro de 1987, ajudei Mabel McKay a colocar uma caixa expositora de vidro contendo amostras de seus cestos no porta-malas do meu carro3 ${ }^{3}$. Lembro-me do ano porque estava prestes a fazer meu exame de qualificação em Stanford. Eu estava ansioso para terminar o trabalho do curso para então poder começar a escrever a história da vida de Mabel, minha proposta de dissertação. Ao longo dos anos eu havia levado Mabel a incontáveis inaugurações em museus homenageando seu trabalho e a várias faculdades e universidades, onde ela falava sobre sua arte de tecelã e sonhadora indígena Pomo, ou seja, de profeta e mulher da medicina.
\end{abstract}

\footnotetext{
1 Tradução de Bianca Pasqualini do ensaio: SARRIS, Greg. "What I'm Talking about when I'm Talking about My Baskets": conversations with Mabel McKay. In: SMITH, Sidonie; WATSON, Julia (Org.). De/Colonizing the Subject: The politics of gender in women's autobiography. Minneapolis: University of Minnesota Press, 1992. p. 20-33.

${ }^{2} \mathrm{Na}$ biografia que escreveu sobre a vida de Mabel McKay e nos inúmeros ensaios publicados, Greg Sarris conta sobre sua infância em Santa Rosa, California, e suas interações com Mabel McKay. Dessa relação emerge não apenas a biografia dessa tecelã e mulher da medicina pomo escrita por Sarris num outro período de sua vida, já como aluno de pós-graduação em Stanford, mas surge também um vínculo complexo que acaba por conduzir Sarris de volta ao lar que nunca conheceu, uma vez que foi criado por pais adotivos sem saber quem eram os seus pais biológicos. Quando ele descobre sua verdadeira ascendência filipina, kashaya pomo e miwok, pelo lado paterno, e irlandesa e judaica-alemã, pelo materno, consolidam-se elos familiares com as famílias indígenas de seu convívio: ela já não é mais um estranho, mas um parente. Ou talvez, para sempre parente e estranho, refletindo sobre as histórias indígenas que ouviu enquanto estranho durante a infância, entrelaçando-as com as histórias indígenas e acadêmicas que ouve enquanto parente. O presente ensaio abre um diálogo que não revela o outro, apontando sempre para nossos pressupostos, nossas incertezas e a possibilidade de reconhecer o outro enquanto mistério. Além da importante biografia Mabel McKay: Weaving the Dream [Mabel McKey: Tecendo o Sonho, 1994], Sarris escreveu o romance Watermelon Nights [Noites de Melancia, 1998], um livro de contos que ele mesmo adaptou para o filme homônimo Grand Avenue [Avenida Grande, 1994 e 1996, respectivamente], além de artigos e livros sobre a literatura e a oralidade indígenas, entre outros temas. Atualmente, Greg Sarris é membro e presidente dos Índios Federados da Graton Rancheria.

${ }^{3}$ Este capítulo foi composto a partir de gravações e memórias de conversas com Mabel McKay em fevereiro de 1987.
}

Espaço Ameríndio, Porto Alegre, v. 7, n. 1, p. 346-364, jan./jun. 2013. 
GREG SARRIS - Do que que eu estou falando quando falo dos meus cestos...

Eu queria que meus colegas da Stanford a ouvissem, todas aquelas pessoas - orientadores e amigos - que me davam sugestões sobre como escrever as histórias que Mabel vinha me contando da sua vida até onde minha memória alcançava. Mas eu também queria que a vissem comigo. Queria que me vissem como índio, alguém na posição de membro da comunidade que entendia Mabel de maneiras inacessíveis a eles. Sou miscigenado (pomo-coast miwok e filipino pelo lado paterno; judeu, alemão e irlandês pelo lado materno) e de pele clara. Por causa da cor da minha pele e da formação acadêmica em comum com meus colegas, eu me perguntava se eles consideravam as diferenças imensas entre seu(s) mundo(s) e o mundo que conheço como índio com Mabel.

Enquanto dirigíamos para o sul, saindo de Rumsey, onde Mabel estava morando naquela época, ela me avisou que não falaria sobre questões espirituais aos estudantes da Stanford.

- Só sobre os meus cestos - ela disse, com uma risada divertida. Vou fazer uma demonstração para eles. Você trouxe minha bacia e as raízes?

- Sim, estão no porta-malas - eu disse.

Ela colocou a bolsa de verniz preta sobre os joelhos, resoluta. Às sete horas da manhã estava impecável: totalmente desperta, sem fazer esforço para estar presente. Vestia um vestido lilás e sobre ele uma jaqueta de nylon elegante. Os óculos quadrados sob cabelos tingidos de preto com permanente davam os ares de uma diretora de escola. As pessoas costumam se surpreender com a aparência dela; imaginam uma índia norte-americana tradicional de outro modo. Não percebem logo de cara o maxilar impenetrável e os cantos da boca virados para baixo, nem os olhos brincalhões. Não enxergam Mabel até que ela comece a falar, respondendo a suas perguntas.

Eu me perguntei se ela estava irritada naquele momento, se ela achava que eu talvez a tivesse forçado a se comprometer com as pessoas de maneiras inapropriadas. Eu sabia que ela poderia ficar brava se eu dissesse algo de que ela não gostasse. Ela me confrontaria diretamente ou esperaria uma chance para me pegar desatento e me dar uma lição. Ela era particularmente adepta da última tática, me atarantando das ma- 
GREG SARRIS - Do que que eu estou falando quando falo dos meus cestos...

neiras mais inesperadas. E ela sempre parecia conhecer as minhas pretensões, o que eu estava pensando.

Então expliquei mais uma vez, apenas para aliviar minha angústia, que havia dito ao professor que ela falaria somente sobre aquilo que quisesse falar. A turma dele estava lendo literatura indígena norteamericana, incluindo os chamados mitos e folclores e várias autobiografias individuais de diferentes tribos. Já que era inverno, e já que Mabel só conta histórias da criação no inverno, pensei que ela gostaria de contar algumas histórias antigas.

- Vou falar dos meus cestos - ela disse, abrindo a bolsa e vasculhando em busca de um cigarro. - Farei uma demonstração.

O professor nos encontrou no estacionamento. Ele era alto; vestia um blazer azul-marinho e calças de sarja. Notei um anel turquesa em seu dedo quando ele estendeu a mão para cumprimentar Mabel. Ele conduziu Mabel através dos carros estacionados em direção ao pátio da universidade. Eu os segui, carregando a caixa expositora de vidro onde estavam os cestos de Mabel. Olhei para os cestos de pena e para as miniaturas, as especialidades de Mabel, e então no cesto do sol, feito de penas vermelhas cintilantes, um cesto raso com cerca de dez centímetros de diâmetro, usado para envenenar pessoas.

- Um desses cegou a minha sogra -, Mabel contou uma vez. - Mas não foi este aqui. Este aqui é só para demonstração, mas tem regras, histórias, também.

Ouvi quando o professor disse a Mabel que havia informado os alunos sobre ela. Mabel parou, largou o cigarro e exalou uma nuvem de fumaça.

- Que legal - ela disse.

Ao entrarmos no imenso auditório, ouvi tocar o sino das dez. Entre os quase duzentos alunos havia muitos professores. Reconheci uma poeta famosa sentada na parte lateral bem perto do palco. Estava incli- 
GREG SARRIS - Do que que eu estou falando quando falo dos meus cestos...

nada para frente, observando Mabel com atenção.

Coloquei a caixa com os cestos na mesa comprida diante do público. Então, abri a sacola plástica da K-mart que estava sobre a caixa e peguei o fardo de raízes de ciperáceas de Mabel, um furador e uma bacia de Tupperware. Saí para encher a bacia com água. Quando voltei, o professor estava apresentando Mabel, que estava de pé, afastada na lateral do palco, fumando um cigarro. Pensei comigo mesmo sobre as leis antifumo.

- Ela é a última da tribo dela. Houve um tempo em que essa tribo chegou a ter seiscentas pessoas. Eram os Cache Creek Pomo e viviam a leste do lago Clear, a pouco mais de 160 quilômetros daqui. Ela é, portanto, a última falante da língua de seu povo. Imaginem ser a última pessoa a falar inglês. Mabel é também uma sonhadora. Ela tem sonhos e visões que lhe dizem como tecer seus cestos e que lhe ajudam com suas curas. Ela é uma doutora, uma mulher da medicina, como a mulher do filme que assistimos, The Sucking Doctor ( $A$ doutora que suga). Na verdade, Essie Parrish e Mabel eram muito amigas. Mabel afirma que viu Essie - que estavam se comunicando em sonhos, se encontrando - antes de se conhecerem pessoalmente. Mabel segue regras que governam a vida dela. Ela precisa rezar antes de realizar o que quer que seja. Já comentei isso com vocês. Ela foi criada pela avó seguindo costumes tradicionais. Logo seu povo compreendeu que ela recebera do espírito o poder de curar e tecer. Como disse a vocês, ela é uma tecelã de cestos mundialmente reconhecida. Seus cestos estão no Smithsonian e em muitos outros museus do país e da Europa. Então, temos a honra de receber hoje esta mulher tão importante, que vai nos falar sobre sua vida e seu trabalho.

O professor virou-se para Mabel, que segurava a ponta acesa do cigarro entre o polegar e o indicador. Ela parecia perguntar o que fazer com aquilo. Peguei o cigarro e o apaguei na canaleta do giz.

Eu me sentei no final da mesa. Mabel ficou de pé diante da cadeira, desatando o fardo de raízes de ciperáceas. Eu sabia que o público estava ansioso, particularmente após a introdução demorada, e não estava acostumado a períodos de silêncio tão longos. Mabel colocou várias fibras das ciperáceas amareladas na água e sentou-se. Puxou a bacia 
GREG SARRIS - Do que que eu estou falando quando falo dos meus cestos...

para perto de si, pegou o furador, e de sua bolsa no chão pegou um fardo enrolado em Kleenex. Devagar, ela retirou os lenços de papel e mostrou o começo de um cesto. Examinou o trabalho que tinha em mãos, acomodou as raízes na água com o dedo médio e então olhou para cima, por sobre os óculos, para o público.

- Certo, alguém tem alguma pergunta?

Os alunos e os professores estavam quietos, imóveis. O professor roía as unhas.

Eu já havia presenciado as travessuras de Mabel antes. Uma vez, ao falar para professores e membros da faculdade de medicina de Stanford, ela rezou e cantou, então falou, como se estivesse em transe, sobre os ditames dos espíritos e sobre seu trabalho como mulher da medicina. Já havia falado por um certo tempo quando parou de repente, oIhou para o público e perguntou:

- Então, quem pode me dizer o que eu recém falei?

O imenso público, composto sobretudo por homens, ficou estupefato.

- Ninguém tem nada para me dizer? - ela perguntou por fim e riu. - Pensei que vocês queriam saber sobre curadores.

Em outra ocasião, quando ela falava diante do público em um museu, simplesmente contou uma história sobre como um dos cestos expostos contou à tecelã que o trançou que tomaria uma vida humana a cada ano em sacrifício a não ser que lhe dessem água uma vez por mês.

- É verdade, acreditem ou não - Mabel disse e então desceu do palco.

Mabel remexeu as raízes na tigela de novo e, então, como se tivesse encontrado o que procurava, puxou uma fibra para fora d'água. Segurou a fibra entre os dentes enquanto pegava o cesto que havia começado e o furador. Ela abriu um buraco na fibra espiralada com o furador e então pegou a raiz que segurava na boca e fez o primeiro enlace. Fez outro laço, e outra. Enlaçou de novo, e de novo.

- Alguém tem alguma pergunta? - o professor falou, encorajando a platéia a se manifestar. 
GREG SARRIS - Do que que eu estou falando quando falo dos meus cestos...

Mabel ocasionalmente olhava para o público. Ela estava remexendo na água outra vez, procurando outro filamento.

Até que enfim, uma mão. Suspirei aliviado. No ritmo em que as coisas estavam indo, achei que Mabel teceria diante da platéia durante todos os cinquenta minutos, o que não era o que eu queria.

Mabel acenou com a cabeça para uma mulher, que se levantou e perguntou a Mabel o que ela estava usando para tecer o cesto.

- Raízes -, Mabel disse. - Tudo começa desde o início com raízes. Como o cesto se faz. Como duas pessoas se conhecendo. - Ela se virou para mim: - Como é mesmo o nome que vocês dão a estas raízes?

- Ciperácea -, eu disse e então repeti para a mulher que estava de pé no fundo do auditório.

- Então para a parte da cor, esta parte vermelha aqui -, Mabel continuou, segurando a pequena peça na mão -, eu uso cercis. Tem que colher na época certa do ano. Ela também tem músicas, rezas, regras de uso.

- Mas o que é isso na sua mão?

- Ah, este furador?

- Sim.

- Faço furos com ele, crio espaços quando faço os cestos enrolados. É só isso? - Mabel perguntou, rindo consigo mesma.

A mulher sentou-se, e Mabel voltou a tecer.

O professor, temendo um silêncio prolongado, resolveu agir.

- Mabel - ele disse -, você é uma tecelã tradicional, o que significa que você tece apenas os desenhos que o espírito manda. Você gostaria de falar algo sobre isso?

Mabel colocou o furador sobre a mesa.

- Sim - ela disse. - Tecelão tradicional apenas tece os desenhos que o espírito manda. Então o que você quer saber?

- Quis dizer que você poderia nos contar um pouco sobre isso.

- Bem, alguns tecelãos modernos e os brancos, eles tece só o que 
GREG SARRIS - Do que que eu estou falando quando falo dos meus cestos...

querem, a ideia que tiverem. Os cestos deles não têm regras, histórias, a história. Ah, às vezes eles vê uma coisa, talvez num livro ou museu, e eles copiam, conforme a própria ideia que tiverem. Mas é uma coisa perigosa, sem respeito. Pode criar problema desse jeito. Estas coisas - ela disse, segurando alto o cesto numa mão - estão viva, estão viva.

Ela pegou o furador, então parou bruscamente. Olhou para o professor, ainda parado onde havia feito a pergunta.

- Agora quem pode me dizer o que quero dizer com "estão viva"?

Uma aluna se levantou.

- Você quer dizer que o cesto está vivo?

- Uh-huh - Mabel respondeu. - Você sabe o que isso significa?

- Ele respira?

Mabel riu alto.

- Que bonitinho - ela disse.

- Ele respira?

A aluna, que vestia uma blusa com batik, desviou impaciente.

- Ele fala?

- Sim, ele bem que fala.

- O que ele diz?

- Ah, fala sobre coisas. Depende do tipo de cesto, com quem ele fala. - Ela fez uma pausa e então continuou: - Você consegue ouvir, mas como VOCÊ vai conseguir ouvir?

Pensei no cesto que Mabel havia dado a sua falecida amiga Essie Parrish trinta anos atrás. Em um transe, Essie viu o cesto transpirando antes de uma epidemia futura.

A estudante sentou-se.

- O que falo quando falo dos meus cestos é da minha vida, as histórias, as regras, como as coisas vive, o que elas causam na gente - Mabel segurou o cesto em direção à plateia outra vez. A vara de salgueiro, comprida e maleável, que formava a base do cesto, sacolejou no ar. 0 
GREG SARRIS - Do que que eu estou falando quando falo dos meus cestos...

professor deu um passo para trás na direção do quadro-negro atrás de Mabel. - Agora quem pode me dizer o que quero dizer aqui?

Mabel abaixou o cesto e começou a tecer. A poeta famosa levantou a mão. Mabel assentiu com a cabeça.

- Mabel, você está dizendo que o espírito é como uma graça...

- Bem, o espírito faz graça, às vezes, eu acho.

Interrompi a conversa na tentativa de encobrir o aparente equívoco de Mabel.

- O que acho que ela quis saber, Mabel, é se o espírito fala com você, lhe dá ânimo, entusiasmo.

- Ah - disse Mabel, como se a tivessem informado que tomaria café no almoço. Ela começou a tecer.

Outra aluna levantou a mão.

- Você consegue ver o espírito?

- Sim, às vezes. Agora vai querer saber qual é a aparência dele? A jovem, àquela altura já com o rosto corado, não respondeu. - Muitas vezes a gente nem sabe o que está vendo, então como VOCÊ vai saber?

Outra aluna:

- Como você aprendeu a tecer? Quem Ihe ensinou? Sua avó? Ouvimos que você foi criada por sua avó.

- Não, espírito me ensina, desde que eu era pequena.

A aluna, uma afro-americana alta, persistiu.

- Você quer dizer que não viu sua avó tecer, que ela não Ihe ensinou a tecer? Mas e os desenhos?

- Sim, eu via ela. Ela me mostra umas coisa, onde achar as raiz onde nós morava aquela época, pegar cercis, essas coisa. Mas tenho que fazer o que sei. Espírito está dizendo. Minha avó, ela uma grande tecelã. Minha mãe, ela uma tecelã também. Mas um monte para a tecelagem delas. Um monte para esta tecelagem aqui - Mabel olhou para baixo, para seu trabalho, e deu mais um laço.

A aluna, que parecia perplexa, sentou-se. Seguiu-se um longo 
GREG SARRIS - Do que que eu estou falando quando falo dos meus cestos...

período de silêncio, e então Mabel contou uma história.

- Vejam, o que aconteceu foi que uma mulher teve um sonho. Essa mulher que eu falo estava sonhando [em preparação para ser uma mulher da medicina]. Uma mulher lá do, deixa eu ver, algum lugar em Ukiah. Bom, o que aconteceu, ela tece um desenho. Mas ele atrai as cobras. Um desenho encantador de cobras. Mas mesmo assim a mulher não acreditou. Ela duvidava, queria vida normal. Bem, esse cesto com penas que ela tece, devia ser pequeno, eu acho. Porque um dia desapareceu. Ela diz para si mesma: "Mas como é que meu cesto, ele não está aqui?" Ela deixa ele lá na cabana onde eles morava.

- Então aconteceu, a irmã dela ficou como louca. Diz vai morar com as cobras. Sonhando com as cobras o tempo todo. Então como aconteceu, isso não sei. Mas ela desapareceu. Eles viu os rastros dela até o alto da montanha, mas ela sumiu. Os rastros, eles simplesmente param, as pessoas diz. Ela sumiu. Eu não sei.

- Então essa mulher, ela começa a chorar, então ela desaba, fica tão doente que nem consegue falar. Tá cega. Mas ela tá vendo alguma coisa. Só que ela não sabe. Ela não consegue dizer, falar sobre isso. Tem coisa errada com ela.

- Nós sabia disso porque aquela vez eles chamaram o Médico, aquele homem do norte, e ele reza. Ele viu isto: a irmã foi levada pelas cobra. Ela é cobra agora, eu acho, vivendo com elas em cima daquela montanha. E a mulher doente, ela tá vendo isso nos sonhos dela. Ela viu até onde tava o cesto.

- Tá no corpo da cobra. Foi assim que isso aconteceu. A cobra vem pegar o cesto e engole ele. Então com o cesto e com a canção daquela mulher, a cobra pegou a irmã dela.

- Então, a mulher, ela nos conta isso depois, como viu a irmã e o cesto. Eu não sei. Mas o homem, ele viu isso, também. Eu me lembro. Eu era muito nova ainda. Mas de todo jeito, o que aconteceu foi que essa mulher teve que começar a cantar as canções dela para trazer a irmã de volta. E a irmã, ela volta, também, sai caminhando do meio do mato, e ela vem carregando aquele cesto. Ele está cheio de canções, pelo trabaIho daquela mulher nesta terra. 
GREG SARRIS - Do que que eu estou falando quando falo dos meus cestos...

Um jovem na primeira fila se levantou.

- Talvez a irmã tenha apenas pregado uma peça na irmã e pegado o cesto - ele disse.

- Por que uma irmã ia querer fazer isso? - Mabel respondeu, entre risos.

- A mulher realmente se transformou numa cobra? - o aluno perguntou, confuso.

- Bem, acho que sim.

- O que houve, quero dizer, o que ela fez? - ele continuou, sentado.

- Eu não sei. Eu não sou uma cobra - Mabel respondeu. - Mas uma vez, aconteceu comigo que meu avô me deu canção de cobra cascavel no MEU sonho. "Essas cobra vão ser ajudantes de você", ele tá dizendo. Então eu via elas, na minha casa, no armário, na banheira quando ela tá quente, por todo lado. Então eu digo "Avô, isso agora são tempos modernos, é melhor você tirar essa canção de mim. As pessoas por aqui não entendem essas coisas. Eles podem até chamar o controle de animais." Seja como for, acho que foi por isso, essa mulher quando tá pronta para morrer ela me dá este cesto. Ela me conheceu aquela época. Ela me diz para manter o cesto dela vivo, para ele não pegar nenhum fiIho dela. Então abençoo ele, faço as regras dele todo mês.

Mabel largou o furador e inclinou-se, olhando para a caixa de vidro.

- É este aqui, bem aqui - ela disse, apontando. - Ela disse que eu usaria ele um dia. Eu não sei.

Mabel terminou de falar. Perguntei à plateia se gostariam de ver os cestos na saída da palestra. Olhei de relance para o pequeno cesto de penas que eu pensava tivesse sido feito por Mabel. Ele estava de cabeça para baixo, a parte da base, ou de fora, tinha um padrão intricado em ziguezague com penas amarelo-ouro e tom azul-esverdeado metálico. O peito de um pedro-ceroulo, a cabeça de um pato-real. Uma mulher, obviamente professora de outra universidade, aproximou-se e foi para trás da mesa, onde Mabel estava amarrando o fardo de raízes com um 
GREG SARRIS - Do que que eu estou falando quando falo dos meus cestos...

nó apertado.

- Mabel - ela disse, inclinando-se como se fosse conversar particularmente com Mabel -, eu estava certa o tempo inteiro. Estou trabaIhando com uma navajo que é tecelã. Ela tece cobertores e estou convencida de que são uma autobiografia.

Mabel pareceu confusa. Imaginei que fosse a palavra autobiografia. Ela largou o fardo dentro da sacola plástica que estava no chão.

- Quero dizer a vida dessa mulher. Como se o cobertor fosse a vida dela.

- Poderia ser. Alguns índios são desse jeito. Se transformam em coisas.

A mulher pareceu constrangida. Ela percebeu que eu estava ouvindo. Mesmo assim, continuou.

- Não, Mabel. Quero dizer que o cobertor representa a vida dela; representa as histórias dessa mulher, assim como você contou sobre os seus cestos. O cobertor é uma história, como um livro.

- Ah, é mesmo? - Mabel perguntou. - Eu não sei. Eu falei isso? Mabel colocou o cesto sobre a mesa. - Cada coisa está vivendo, falando. Você precisa conhecer regra. Não conheço essa dona que você falou. Mas se ela está vivendo, se o tal cobertor está vivendo, como você sabe o que ele é? Você é a tal dona? - Mabel estava séria, impassível. Então caiu na risada. - Só estou testando - ela riu.

A afro-americana que havia perguntado se a avó de Mabel a ensinara a tecer aproximou-se então. Ela havia observado Mabel interagir com a primeira mulher. Mabel começou a embrulhar o cesto inacabado com lenços de papel. Ela parou e olhou para cima.

- Mabel - a jovem disse -, me sinto... Quer dizer, vai acontecer alguma coisa comigo se eu olhar para os cestos dentro da caixa de vidro?

- Já aconteceu - Mabel disse. - Obrigada por perguntar.

Mabel terminou de embrulhar o cesto com os lenços e prendeu com um atilho. Largou o furador na sacola plástica, então abriu a bolsa e cuidadosamente colocou o cesto ali dentro. Ela me disse para regar 
GREG SARRIS - Do que que eu estou falando quando falo dos meus cestos...

uma planta com a água da bacia. Umas poucas pessoas se demoraram por ali com o professor, observando os cestos.

- Preciso fumar - Mabel falou, fechando a bolsa com um estalo e se afastando da mesa.

Em algum lugar entre Berkeley e Albany paramos para almoçar. Eu queria perguntar a Mabel a respeito da história da mulher que lhe dera o cesto, a mulher cuja irmã seguiu as cobras. Eu não havia escutado a história antes, e ela me surpreendeu; após trinta anos ouvindo as histórias de Mabel, e após ter tomado notas sobre essas histórias, algumas das quais eu havia escutado centenas de vezes, de algum modo eu havia deixado aquela passar. Eu só queria saber o que Mabel estava fazendo naquela época de sua vida. Que idade ela tinha? Ela acreditava na história?

Não perguntei então. Eu sabia que ela estava cansada de falar e com fome. Ela degustava um frango frito com salada.

Pensei nos alunos e professores que deixáramos em Stanford. O que eles vivenciaram eu já havia presenciado antes. Como sempre, Mabel fora previsivelmente imprevisível; ela agira de modo inquietante, invertendo a dicotomia sujeito-objeto estabelecida pela apresentação do professor: como uma relíquia, uma representante de um passado préhistórico, de quem os alunos e os outros poderiam extrair informações. Como consequência disso, ela suspendeu, ou ao menos interrompeu momentaneamente, em seu encontro com a plateia, a projeção de significado, o que, afinal, não é tão diferente da projeção de uma faca ou de uma bala no sentido de que podem neutralizar antagonismos. Ela situou o passado no presente, expondo aquilo que compõe as diferenças entre sua vida e visão de mundo e as dos seus interlocutores, nunca permitindo, durante o encontro, que sua individualidade ou sua vida fossem apropriadas ou percebidas de outro modo que não o que são, em toda sua complexidade e diferença. Se, como aponta Arnold Krupat, "o movimento [euro-americano] em direção ao Oeste foi alcançado não ape- 
GREG SARRIS - Do que que eu estou falando quando falo dos meus cestos...

nas pelo poder da espada, mas também pelo da escrita", então Mabel é um movimento de resistência por si própria (KRUPAT, 1985).

Mabel tem sido perseguida por historiadores da arte, curadores, colecionadores particulares, linguistas, antropólogos, folcloristas e biógrafos desde sempre. No entanto, como um antropólogo uma vez me disse, "é impossível decifrá-la. Não consigo acompanhá-la." Talvez o que esse sujeito vivenciou tenha sido o que Vincent Crapanzano chama de "vertigem epistemológica" diante do Outro (CRAPANZANO, 1977). A experiência de Mabel, sua percepção do mundo, não é apenas diferente, entretanto. Apresentada com autoridade, não se renderá às pressuposições culturais dos interlocutores e ao poder associado a tais pressuposições. A dinâmica de Mabel, seu discurso, seja uma história, uma resposta a uma pergunta ou uma observação, não só vai na direção de um contato cultural, mas reivindica a história desse contato no que diz respeito a suas relações de poder.

Mabel disse ao professor que os cestos estavam vivos. Naquele momento ela estava chamando a atenção para diferentes concepções culturais do que constitui vida e objetos materiais e o relacionamento entre eles e o tecelão. Mas ela também o estava interrogando, pedindoIhe que dissesse "o que eu recém falei", revelando por meio disso o conhecimento culturalmente específico do professor e o modo como molda seus esforços interpretativos de maneiras peculiares. Quando Mabel disse que o cesto estava vivo, ela quis dizer que o cesto estava vivo. 0 professor teria que começar por tomar aquela afirmação no nível literal, passando a perceber a partir disso a diferença entre o seu mundo e o dela. A subjetividade do professor foi exposta, e Ihe foi solicitado, em seu encontro com Mabel, a se responsabilizar por sua subjetividade. 0 mesmo aconteceu quando a aluna perguntou a respeito da influência da avó de Mabel. A aluna presumiu uma distinção entre a aquisição da arte da tecelagem através da demonstração da avó e a imitação e o amadurecimento da jovem Mabel na arte da tecelagem através de um compromisso espiritual com o processo.

A resposta de Mabel à professora que trabalhava com a tecelã navaja desvelou outra estratégia de apropriação. Diante da diferença, a professora criou uma nova categoria que esclarecesse ou explicasse a 
GREG SARRIS - Do que que eu estou falando quando falo dos meus cestos...

diferença. Portanto, ela lê tapetes navajos como autobiografias. Uma autobiografia, como é entendida na tradição ocidental, pressupõe uma noção de individualidade culturalmente específica e certas expectativas dos leitores. Se a tecelã navaja estava ou não tentando representar sua vida nos tapetes é incerto. E caso ela estivesse, seria uma individualidade familiar à construída na tradição de autobiografia que a professora conhece?

O relacionamento da tecelã navaja com seus tapetes, assim como o relacionamento de Mabel com seus cestos, é entendido e vivenciado de maneiras pessoais e particulares à sua cultura e história e, imagino, não é legível no sentido ocidental ou euro-americano do termo. Mas, de novo, será que podemos compreender o que quer que seja sobre um relacionamento ou percepção de individualidade tão diferentes se a professora simplesmente nomeou o que viu sem explorar suas próprias definições ao deparar com as definições da tecelã navaja? $O$ ato de nomeação - ou, nesse caso, apropriação - causa um grande estrago. Silencia e turva não só o sujeito individual e as qualidades peculiares da sua voz e vida, sozinha ou em contato com a professora, mas também a dinâmica de poder que permite que as pessoas nomeiem outras para início de conversa. A professora e seus leitores correm o risco de esquecer que, como Mabel indicou, a professora não é a tecelã navaja.

Já vi outros supostos palestrantes pomo interagir com gente de fora interessada. Conheci mulheres que inventaram histórias para antropólogos, ganharam quantias módicas pelas histórias e riram depois. Uma delas me disse:

- Nossas histórias, como nossas vidas, estão vivendo. Bem podemos dar uma perna ou um braço ao homem branco. Não importa o que ele ganhe, ele faz com isso o que quiser. Como fez com nossa terra.

Outra mulher pomo, Essie Parrish, me disse que nunca mentia, mas contava trechos aqui e ali.

- Só o que perguntavam -, ela disse. - Como é que eles [os antropólogos] vão conseguir ver a árvore quando estão olhando só para uma folha?

Essas mulheres pomo, ao interagirem com grupos não-pomo, a- 
GREG SARRIS - Do que que eu estou falando quando falo dos meus cestos...

daptam o discurso, seja fabricando informações, seja apresentando informações de certas maneiras. Mas o que Mabel faz é bastante diferente. Ao expor o que constitui as diferenças entre sua vida e visão de mundo e as dos seus interlocutores, ela continuamente abre uma via de discurso com os outros. Ela provoca trocas, oferecendo a oportunidade para que as pessoas vejam e falem sobre visões de mundo distintas conforme surgem em momentos compartilhados.

Por um longo tempo tentei descobrir um modo de escrever a autobiografia de Mabel. Eu estava, afinal, na posição de leitor da vida de Mabel, uma vez que escreveria, ou a decifraria, para os outros. Mas e os problemas de linguagem? Mas e a estrutura narrativa, especificamente as apresentações não-cronológicas e fragmentadas de Mabel? E o meu papel de ouvinte?

Eu me lembro da época em que pensava ter todas as respostas. Estava em casa após minha primeira temporada na faculdade. Recém havíamos chegado de uma escola onde Mabel estava fazendo uma demonstração da tecelagem de seus cestos. Foi uma viagem longa, e, segundo me recordo, era bem tarde quando finalmente chegamos em casa. Eu estava sentado, tomando uma xícara de café e rindo das perguntas idiotas que as pessoas fizeram a Mabel.

- Eu poderia escrever o seu livro - falei então. - Sei mais sobre você e sobre nosso modo de viver do que aqueles acadêmicos idiotas.

Ela estava abrindo a caixa de vidro à sua frente sobre a mesa da cozinha. Eu a vi retirar um cesto miniatura. Sem dizer uma palavra, ela se levantou e prendeu o cesto e uma fita à minha camisa.

- Pense nisso - ela disse.

Claro, naquela tarde no Denny's eu ainda estava preocupado com a necessidade de dar sentido à vida de Mabel. Ao menos, naquele momento, eu ainda sentia que precisava conhecer as partes, ainda que só na minha cabeça. Eu poderia criar uma cronologia coerente, sua vida do início ao fim.

- Mabel - falei -, eu nunca tinha ouvido aquela história sobre a mulher que ficou cega, sobre a mulher e o cesto. 
GREG SARRIS - Do que que eu estou falando quando falo dos meus cestos...

Ela havia terminado de comer e estava bebericando o café. Colocou a xícara na mesa.

- Ah, aquilo - ela disse, lembrando-se de repente.

- Que idade você tinha quando aquilo aconteceu?

- O que? - Ela estava acendendo um cigarro.

- Quando você conheceu aquela mulher, quando o problema com o cesto aconteceu.

- Muitos problemas - Mabel respondeu, começando a rir. Ela soltou a primeira tragada de fumaça, levantando o queixo, como se apontasse acima de nós. Parecia interessada em conversar. Estava rindo de algo.

- Bem, então, quando você conheceu a mulher? Foi em Ukiah?

- Não. Acho que foi em Middletown. Não me lembro. Eu não sei. Em algum lugar, enfim.

- É por causa do seu livro. Você quer que eu escreva o seu livro. Lembra? Conversei com você sobre como vamos fazer. Eu preciso pegar todas as pessoas e lugares que você conhece...

- Conheço muitos - Mabel interrompeu, batendo o cigarro no cinzeiro.

- Você era jovem?

Ela ignorou a pergunta, ou assim pareceu. Deu uma tragada no cigarro.

- Veja, quando aquela dona ia morrer ela me deu aquele cesto. Ela diz que ele tá falando, aquele cesto. Fala o tempo todo. Usa um dia, ela me diz. É útil. Então alimento ele e levo ele comigo e assim afasto os problemas da família dela. Um dia, uma mulher lá, do povo daquela dona, ela vai querer saber. Então eu paro de fazer. Agora está fazendo comigo. Agora eu vi o que aquela mulher está dizendo.

- Ah, você quer dizer a maneira...

- O que que eu estou dizendo agora?

- Ah, você quer dizer a maneira como você usou o cesto hoje na 
GREG SARRIS - Do que que eu estou falando quando falo dos meus cestos...

palestra, para contar a história?

Mabel olhou para mim e apagou o cigarro. Estava séria, com olhar desaprovador.

- Como que você vai escrever o meu livro? - Ela perguntou, ou repetiu. - Estou demonstrando - então caiu na risada. - Se fosse uma cobra, te mordia - ela riu.

Eu me senti atordoado, estúpido. Ela estava certa. Eu não estava conseguindo ver o que estava bem na minha frente. Pensei sobre os outros, meus colegas em particular, e sobre Mabel. Mas tomei eu e Mabel como certo. Eu não era Mabel, mesmo sendo índio. Não só por causa da minha herança miscigenada e pele clara. Havia outras coisas: geração, gênero, minha formação universitária. Eu ainda nutria a noção de que coisas como uma cronologia da vida de Mabel e um índice de todas as pessoas e lugares que ela conhecia me dariam uma compreensão separada da minha interação com ela. Ela percebia isso naquele momento? Fui deliberadamente interrompido?

Lembrei-me de uma história. Era sobre um culto de médicasursas que compartilhavam uma caverna em Cache Creek, Lake County. Médicas-ursas vestiam a pele e a cabeça do urso pardo e, com certos cantos, adquiriam grandes poderes. Conseguiam caçar e procurar nozes e outros alimentos em lugares distantes. Podiam mover-se em grande velocidade. Matavam inimigos. Ouvia-se mais sobre médicos-ursos. Mas Mabel falou que estas eram mulheres. Eram mulheres de vários grupos e tribos vizinhas. Observavam outras mulheres e escolhiam seus membros cuidadosamente. Ninguém sabia que mulheres faziam parte do culto. Qualquer mulher poderia ter poderes de urso.

Uma manhã, bastante cedo, um homem saiu para pescar. Ele encontrou a esposa, que estava ajoelhada perto da água. Ele parou e escondeu-se atrás de uma rocha para poder ver o que ela estava fazendo. Ela estava lavando uma pele de urso. Ele não acreditou no que via. Então a seguiu e entrou na caverna em que ela havia entrado. Ele não voltou para casa naquela noite. Ao longo do ano seguinte, pedaços do homem, primeiro um dedo ou um olho, depois um braço ou um dente, apareceram nos arredores da aldeia. As pessoas acharam que era ele, que ele 
GREG SARRIS - Do que que eu estou falando quando falo dos meus cestos...

havia sido despedaçado por homens-urso, mas nunca confirmaram sua identidade. Então nunca houve um funeral. Ele cometeu o erro de não acreditar que a esposa era um urso e de segui-la, Mabel disse. Ele não a respeitou.

As histórias de Mabel iam e vinham com as minhas próprias histórias. Tornavam-se minhas também. A história sobre a mulher e o cesto tanto me envolvia quanto era sobre mim. Como a mulher na história, eu queria que minha vida - digamos, meu trabalho com Mabel - fosse normal, diferente e separada daquilo que eu estava vivenciando com ela. Sem dúvida senti um conflito entre a minha noção adquirida de autobiografia, intimamente associada com minha formação acadêmica, e a noção de Mabel de como uma história de vida ou histórias de vida são significativas. Mas eu estava cego quando cedi à primeira noção, incapaz de enxergar. Do mesmo modo que a mulher não podia falar sobre o que viu, eu não podia escrever sobre Mabel. Para Mabel, uma vida não existia nem poderia existir no vácuo, como um objeto, mais do que um cesto ou uma história poderiam. Esta foi uma ideia que tive no Denny's aquele dia.

Pensei nas penas amarelo-douradas e azul-esverdeadas, o padrão em ziguezague do cesto. Era nossa história, sobre mim e Mabel juntos. Era sobre a escrita do "seu livro", não apenas sobre mim ou sobre ela, mas uma história intricadamente entrelaçada, de diferentes materiais, como em qualquer cesto de qualidade. E a lição, por conseguinte, tornou-se a história para um artigo.

- Você tem grandes ideias - Mabel disse então. - Como todo mundo tem ideias. Como as pessoa que vão ler o que você escreve sobre nós - ela riu, então verificou se a conta estava paga e escorregou no assento para levantar-se da mesa. - Pense no seu cesto - ela disse. Agora vamos embora antes que alguma outra coisa comece a fazer uma demonstração - ela caiu na risada de novo. Ela se sacudia tanto rindo que não conseguia andar. - Talvez comece a fazer uma graça.

\section{Referências bibliográficas}

Espaço Ameríndio, Porto Alegre, v. 7, n. 1, p. 346-364, jan./jun. 2013. 
GREG SARRIS - Do que que eu estou falando quando falo dos meus cestos...

CRAPANZANO, Vincent. The Life History in Anthropological Field Work. Anthropology and Humanism Quarterly, Washington, v. 2, n. 2-3, p. 3-7, 1977.

KRUPAT, Arnold. For Those Who Come After. Berkeley: University of California Press, 1985.

SARRIS, Greg. "What I'm Talking about when I'm Talking about My Baskets": conversations with Mabel McKay. In: SMITH, Sidonie; WATSON, Julia (Org.). De/Colonizing the Subject: The politics of gender in women's autobiography. Minneapolis: University of Minnesota Press, 1992. p. 20-33. 